\title{
PARCELAMENTO, EDIFICAÇÃO E UTILIZAÇÃO COMPULSÓRIOS (PEUC): AVALIAÇÃO E RESULTADOS DA APLICAÇÃO EM PALMAS-TO
}

\section{MANDATORY PATH TO PLAN, BUILD AND USE (PEUC): ASSESSMENT AND RESULTS OF APPLICATION IN PALMAS-TO}

\author{
João Aparecido Bazolli ${ }^{1}$
}

\begin{abstract}
Resumo
Este trabalho objetivou avaliar a aplicação do instrumento urbanístico de Parcelamento, Edificação e Utilização Compulsórios (PEUC) no seu papel precípuo de indutor à mudança de comportamento dos agentes econômicos no cumprimento da função social da propriedade e o de mostrar os resultados de sua aplicação na racionalização da ocupação dos espaços vazios urbanos em Palmas, Tocantins. Justifica-se esse estudo pelo fato do Estatuto da Cidade completar 15 anos de vigência em julho de 2016 ainda com aplicabilidade tímida, principalmente, no uso deste instrumento pouco incorporado às políticas públicas de ordenamento do território. A metodologia de abordagem qualitativa e quantitativa aplicada a este estudo empírico consistiu na análise do PlanoDiretor de Palmas e da Legislação Urbanística brasileira vigente para compreender e entender a sua aplicação e resultado. Concluímos, ao constatar o fato de mesmo diante de uma legislação inovadora, contextos políticos e ideológicos favoráveis, que o PEUC não conseguiu cumprir o seu papel precípuo de indutor à mudança de comportamento dos agentes econômicos, em razão da forte resistência do setor imobiliário e da reduzida escala local da aplicação no âmbito territorial em Palmas, perdendo a sua efetividade como indutor ao pleno cumprimento da função social da propriedade.
\end{abstract}

Palavras-chave: Estatuto da cidade, Plano Diretor, Legislação Urbanística, Peuc, Iptu progressivo.

\section{Abstract}

This study aimed to evaluate the implementation of the urban instrument "Mandatory path to Plan, Build and Use" (PEUC) in its primary role of inducing the change of behavior of economic agents in the fulfilment of the social function of property and to show the results of its application in the rational occupation of urban empty spaces in Palmas, Tocantins. This study is justified by the fact that the City Statute (Law 10.257), completing 15 years of operation in July 2016, is still experiencing an underused applicability, especially into public policy planning. The qualitative and quantitative methodological approach applied to this empirical study was the analysis of the City Master Plan of Palmas-TO and the current Brazilian Urban Legislation to comprehend their application and results. We concluded that even in face of an innovative legislation and a political and ideological favourable context, the PEUC failed to fulfil its primary role of inducing the change on the behavior of economic agents, because of the strong real estate resistance and reduced local scale application in the territorial scope of Palmas-TO, losing its effectiveness as an inducer to full compliance with the social function of property.

\footnotetext{
${ }^{1}$ Professor Adjunto na Universidade Federal do Tocantins (UFT) do Curso de Direito. Docente Permanente no Programa de Mestrado em Desenvolvimento Regional (PPGDR/UFT). Pós-doutorado na Universidade de Lisboa. Líder do grupo multidisciplinar: Cidade e Meio Ambiente (CNPq). Coordenador do (GT-Cidades) no Instituto de Pesquisa, Diretos e Movimentos Sociais (IPDMS). Vice-coordenador do Núcleo de Estudos Urbanos e das Cidades - Neucidades/UFT. Mebro da equipe do Projeto Nós Propomos - IGOT/Universidade de Lisboa - Portugal. Presidente da Comissão Especial de Direito Urbanístico (CEDU) da OAB/TO. Membro da Comissão Especial de Planejamento Urbano e Ambiental (CEPUA) do CAU/TO. E-mail: jbazolli@uft.edu.br
} 
Revista de Direito da Cidade

vol. 08, ำ 4. ISSN 2317-7721

DOI: $10.12957 /$ rdc.2016.23493

Palavras-chave: City Statute, Master Plan, Urban Legislation, Peuc, Property Tax. 


\section{INTRODUÇÃO}

Este trabalho objetivou avaliar a aplicação do instrumento urbanístico de Parcelamento, Edificação e Utilização Compulsórios (PEUC) no seu papel precípuo de indutor à mudança de comportamento dos agentes econômicos e o de mostrar os resultados de sua aplicação na racionalização da ocupação dos espaços urbanos em Palmas, Tocantins. Este instrumento urbanístico ainda pouco incorporado às políticas públicas de ordenamento do território em escala local tem a função de desincentivo à retenção especulativa, obrigando os proprietários a dar destinação aos seus imóveis abandonados, terrenos vazios sem edificação ou glebas sem utilização e parcelamento, de forma a cumprir a função social.

Palmas foi a primeira capital brasileira e a única cidade do estado do Tocantins a implantar o PEUC. Buscou-se então, neste estudo, focalizar a importância da implantação desse instrumento como medida coercitiva à observância da função social da propriedade nesta cidade. Nesse contexto, analisou-se o uso do PEUC também na sua finalidade de mitigar os conflitos das disputas pelos espaços urbanos, porque possibilita a redução da retenção especulativa e inibe o avanço do processo da periferização na cidade, em razão de esses fatores serem responsáveis pelo aumento da demanda por urbanização a um custo extremamente elevado.

Estruturamos o debate proposto na premissa de que a Lei № 10.257 (BRASIL, 2001), conhecida como Estatuto da Cidade e reguladora do PEUC, seja uma legislação inovadora e indutora às mudanças de paradigmas, especialmente por possibilitar no seu conjunto de ferramentas a universalização do acesso à terra urbanizada. Outro elemento estrutural importante no uso desse instrumento é o de que, embora a aplicação do PEUC resulte em obtenção de recursos, tanto financeiros, como patrimoniais, pela aplicação do Imposto Predial e Territorial Urbano (IPTU) progressivo e consequente desapropriação-sanção, jamais deveria ser aplicado com o intuito específico de aumentar a arrecadação municipal. Porém, pode-se constatar essa intenção na aplicação desse instrumento em Palmas, como veremos adiante, quando demonstrada, pelo discurso dos gestores locais, a clara pretensão arrecadatória, e com o agravante de não haver planejamento no município para o uso dos possíveis recursos patrimoniais arrecadados pelas desapropriações-sanção.

A metodologia de abordagem qualitativa e quantitativa aplicada a este estudo empírico consistiu na análise do Plano-Diretor de Palmas e da Legislação Urbanística brasileira vigente para compreender e entender a aplicação do PEUC no seu papel precípuo de indutor à mudança de 
comportamento dos agentes econômicos, especialmente os do setor imobiliário. Para fundamentar o estudo, procedeu-se à revisão de literatura atual para uma breve análise de conceituação acerca desse instrumento urbanístico, no intuito de provocar uma reflexão críticodialética acerca das atuais práticas disseminadas pelo governante local.

Para melhorar a compreensão do leitor, estruturou-se este trabalho com uma breve caracterização da cidade de Palmas, a partir do seu modelo de ocupação periférico, do histórico legislativo da criação da Lei que trata do assunto e como está sendo implantado o PEUC, e, ao final, demonstraram-se os resultados parciais alcançados com a utilização do instrumento e os seus reflexos no planejamento da cidade.

Para atingir o objetivo deste estudo, realizado para constatar o fato de que mesmo diante de uma legislação inovadora, contextos políticos e ideológicos favoráveis, o PEUC não conseguiu cumprir o seu papel precípuo de indutor à mudança de comportamento dos agentes econômicos, em razão da forte resistência do setor imobiliário e da reduzida escala local da aplicação no âmbito territorial em Palmas. Por esse motivo ainda não é perceptível a sua efetividade como indutor ao pleno cumprimento da função social da propriedade.

\section{A FUNÇÃO SOCIAL NO CONTEXTO DE UMA NOVA ORDEM URBANÍSTICA}

No Brasil, os registros de normas sobre assuntos urbanos remontam o período colonial. Destacam-se, nesse contexto, as Ordenações Filipinas que, pela sua importância, estiveram vigentes no Brasil até 1916 e tratavam de matéria edilícia, da organização da cidade e das atribuições das autoridades locais relacionadas às deliberações sobre as questões urbanas (DI SARNO, 2004).

A cronologia do atual debate sobre a função social da propriedade no contexto histórico brasileiro remonta 1808, ano este considerado como divisor de águas entre a propriedade absoluta e relativa. Instituiu-se, nessa época, o princípio do "poder de polícia" que fundamenta a aplicabilidade dos institutos jurídicos urbanísticos, além de nascer, na ocasião, a cultura jurídica da função social da propriedade urbana criada pela jurisprudência. Essa nova cultura em questão estabeleceu a prerrogativa ao Estado, por razões intrínsecas, de arbitrar sobre os interesses comuns (DIAS, 2000).

Desta feita, a temática urbana brasileira, que era tratada de maneira fracionada, alcançou definitivamente o status de marco regulatório urbanístico a partir da Constituição do Império de 1824, século XIX, que passou a amenizar o tratamento do direito de propriedade, que antes tinha o 
caráter quase que absolutista. Segundo Di Sarno (2004) A Carta Política de 1824 dispõe, por previsão legal do instituto da desapropriação, autêntica intervenção estatal. Esse instrumento possibilitaria ao Estado lançar mão de áreas de seu interesse, com a retenção de propriedade privada, contrariando, assim, o dito princípio absolutista.

Mas, somente no final do século XIX a legislação urbanística brasileira mostrou sua evolução com o registro de parcerias entre o poder público municipal e a iniciativa privada. Para Dias (2000) tais parcerias ocorreram pela necessidade de melhorias urbanísticas nas cidades portuárias, chamadas de cidades de fluxo. Essa intervenção possibilitou a realização de obras públicas nas cidades pelas empresas privadas que recebiam, em contrapartida, concessões para a exploração de serviços públicos na área portuária.

A primeira Constituição Republicana (BRASIL, 1934) ratificou e contemplou definitivamente a função social da propriedade, grafada no texto, de maneira explícita, no artigo 133, item 17, mas foi interpretada de maneira implícita quanto à sua aplicabilidade.

[...] item 17 - É garantido o direito de propriedade, que não poderá ser exercido contra o interesse social e coletivo, na forma que a lei determinar, assegurando a defesa prévia e justa nos casos de desapropriação por necessidade de utilidade pública.

Surgiriam novas intervenções, ainda que modestas, no campo jurídico, somente na década de 1960, entre elas a implantação da Política Nacional de Habitação e Planejamento Territorial. No entanto, mesmo com este arcabouço à disposição, somente no final dos anos 1970, nossos legisladores admitiram a existência de considerável parcela da população sem acesso ao mercado formal de solo. Porém, o Direito urbanístico através daquilo que se convencionou chamar "legalidade urbana" é regido por uma racionalidade instrumental, voltada para a otimização do lucro e do poder no espaço urbano, produzindo a segregação urbana e por isto a necessidade de um novo paradigma. (DIAS, 2000, p. 224).

Mas, finalmente a política urbana é protagonizada na Constituição da República Federativa do Brasil (BRASIL, 1988), nos artigos 182 e 183, que introduz o princípio da função social.

Segundo Harada (2004), a função social da propriedade, quando expressa no Plano-diretor, evita a especulação imobiliária, pois possibilita a aplicação das medidas coercitivas previstas pela Lei no 10.257 (BRASIL, 2001), Estatuto da Cidade, que após uma longa tramitação no legislativo federal, exatamente onze anos, foi aprovada.

O Estatuto da Cidade surgiu como uma nova lei para ordenar o crescimento do setor imobiliário e estabelecer as diretrizes gerais da política urbana nacional. Tem a finalidade de regulamentar as questões da ordenação do território e da participação comunitária, e objetiva 
promover a inclusão social. Também estabelece as regras referentes ao uso e a ocupação do solo urbano e ao controle da expansão do território urbano, e propõe a definição da função social da cidade e da propriedade, a ser especificada no Plano-diretor municipal.

A Lei coloca à disposição, no seu capítulo segundo, ferramentas e instrumentos de Política Urbana para uso contra os abusos ao direito à propriedade, como a especulação imobiliária derivada da retenção fundiária. A especulação imobiliária objetiva a valorização viciosa do imóvel e, em regra, é provocadora dos vazios urbanos nas regiões centrais das cidades. Esse procedimento de retenção fundiária, pela nova Lei, poderá ser punido com o Imposto Predial Territorial Urbano progressivo, pelo fato da propriedade não cumprir a função social.

O Estatuto da Cidade dispõe que a municipalidade fixará as condições e prazos para o cumprimento da obrigação de parcelar, edificar ou utilizar terra urbana mantida em ociosidade, sendo assegurados os prazos não superiores há um ano para protocolização de projeto de parcelamento, utilização ou construção. O contribuinte tem dois anos, a partir da aprovação do projeto, para a utilização, parcelamento ou dar início às obras de edificação.

É importante notar que a norma legal ressalta a obrigação de utilização da terra urbana de forma independente do parcelamento ou edificação. Não cumpridas as obrigações estabelecidas, o município procederá à aplicação do Imposto Predial e Territorial Urbano progressivo no tempo, que poderá resultar na desapropriação-sanção do imóvel. Se optar por esta penalidade, deverá pagar o valor da indenização, que corresponde ao valor venal do imóvel (valor encontrado na planta de valores genéricos e utilizado para a cobrança do imposto predial), na forma de títulos públicos.

O avanço na sistemática desse pagamento pode ser verificado na previsão legal que possibilita a dedução da valorização do imóvel, em função de obras realizadas pelo poder público no local (pavimentação, iluminação pública, rede de esgoto, etc.). Portanto, encontrado o valor correspondente à indenização do imóvel, caberá a dedução da valorização atribuída entre o período da certificação do recebimento da notificação ao proprietário que impôs o aproveitamento do imóvel e a efetiva desapropriação.

Nesse viés, foi considerada também como grande avanço do Estatuto da Cidade, a determinação da dedução, no pagamento da desapropriação-sanção, de quaisquer expectativas de ganhos, lucros cessantes e juros compensatórios, relativos ao imóvel desapropriado.

Com essa medida, fica caracterizada a expropriação da "mais valia", objeto do lucro resultante da valorização do imóvel, por conta de melhorias na localidade onde está inserido, 
realizadas pela prefeitura e pagas por todos os contribuintes. Dessa maneira, a destinação dessa valorização, atualmente apropriada pelo agente privado, toma outra direção, vai para os cofres públicos municipais e retorna para os contribuintes em forma de prestação pública.

\section{A CIDADE DE PALMAS E OS DILEMAS DA OCUPAÇÃO DO TERRITÓRIO URBANO}

Palmas, capital do estado do Tocantins - criado pela divisão de Goiás na Constituição Federal (BRASIL, 1988) -, é a mais recente capital brasileira com área de 2.218,94km² e densidade demográfica de 102,9 hab/km², e está localizada na Região Norte do País, localização mostrada na Figura 1. Embora seja uma cidade planejada com apenas 27 anos de fundação e 272.726 habitantes (IBGE, 2015), constatam-se, por estudos realizados (SEGAWA, 1991); (MORAES, 2003); (TEIXEIRA, 2009); (CYMBALISTA, 2010); (BAZOLLI, 2015), problemas estruturais de crescimento desordenado, com reflexos econômicos, ambientais e sociais.

\section{Figura 1. Mapa de localização de Palmas}

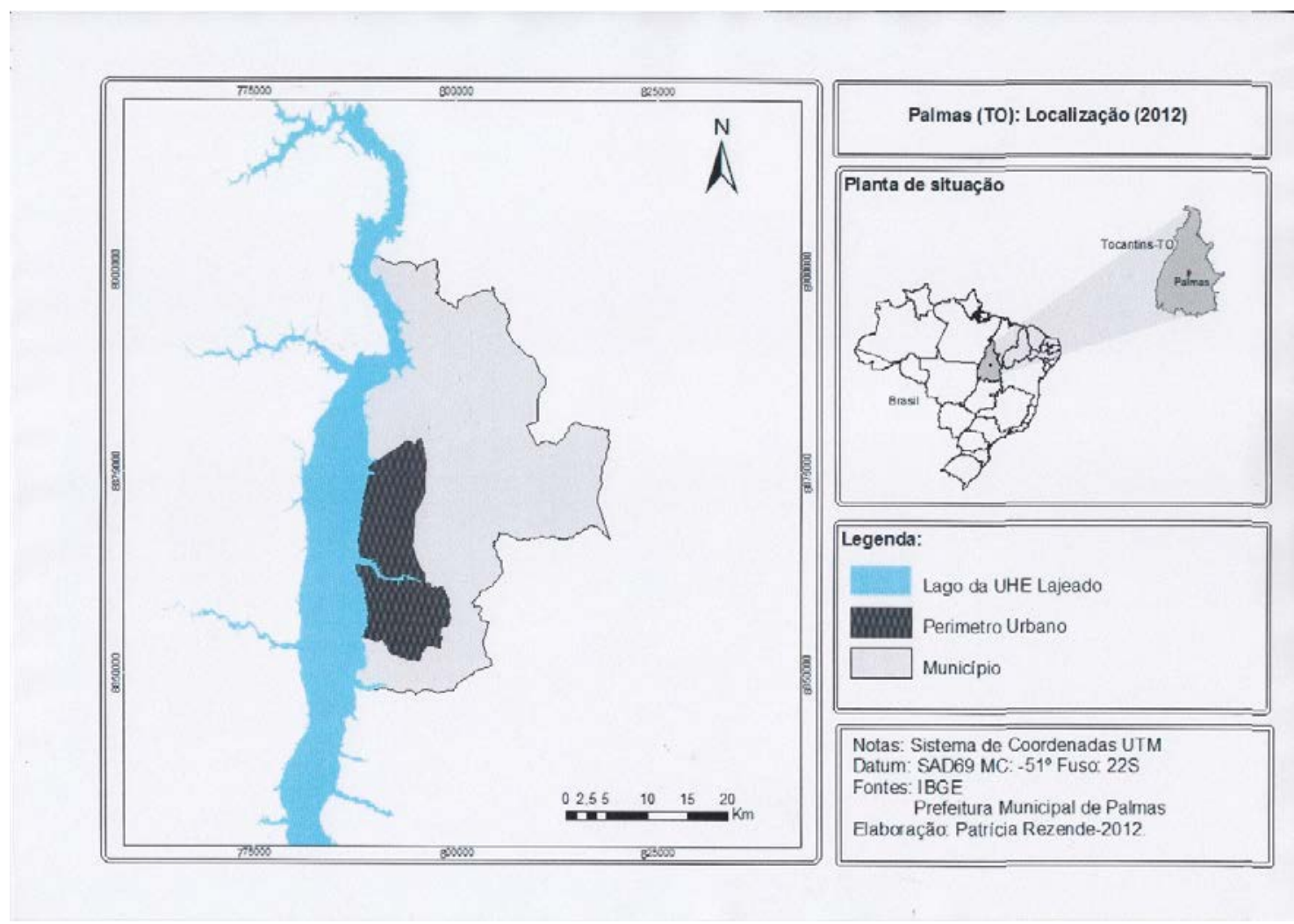

Fonte: IBGE, 2015

Para o leitor compreender a importância da aplicação do PEUC na cidade de Palmas, seria necessário entender o seu processo de ocupação periférica, com retenção especulativa na região 
central, e a prática da valorização imobiliária baseada na fictícia escassez de terra. Por esse motivo, explicaremos em breve considerações acerca da dinâmica de ocupação da cidade.

A capital do Tocantins foi instituída, em 1989, por meio de desapropriação de fazendas e passou a ser construída a partir de um modelo linear periférico. Foram criados bairros longínquos do centro administrativo para acomodar parte da mão de obra imigrante, vinda para construir a nova cidade. Segundo Bazolli (2015), há uma clara segregação socioespacial na cidade que "concentra atualmente o núcleo rico, classe dominante, no seu plano urbanístico, região central, e os pobres, proletariado, foram e continuam a ser expulsos para locais distantes". (Ibid. p. 56). Este mesmo autor constata em estudos realizados que "97,12\% da população do município" é urbana; desta população apenas "11,59\%" vivem no plano urbanístico original (conhecido na cidade como Plano-Diretor), previsto para ser ocupado por 1,2 milhões de pessoas. Isso significa um percentual de "88,41\%" (Ibid. p. 55) de ociosidade na ocupação da cidade, em termos de densidade demográfica.

A cidade de Palmas possui uma dinâmica de ocupação urbana peculiar a partir do seu plano urbanístico original criado em 1989. Definiu-se inicialmente neste plano um perímetro urbano de 110,8km², mas esse espaço se multiplicou por várias vezes. Logo em 1992 ocorreu uma expansão linear da cidade para a região sul, que agregou à sua dimensão geográfica mais $117,4 \mathrm{~km}^{2}$ (maior do que a cidade original). Foram criados nesta região bairros emblemáticos: Aurenys; Santa Barbara e Taquari, dentre outros, todos destinados à população de baixa renda. Em 2002, com a instituição de um plano de macrozoneamento (PALMAS, 2002), a cidade chegou a ter extensão linear urbana de 35 quilômetros, por ver acrescido um novo perímetro urbano na sua região norte. Porém, de maneira racional, o Plano-Diretor municipal, aprovado em 2007 (PALMAS, 2007), reduziu o perímetro urbano da cidade e fez com que a região norte, em questão, retornasse à condição de área rural.

O desrespeito ao planejamento e falta da gestão do território urbano causaram efeitos perniciosos à sociedade e ao crescimento econômico, refletindo-se nos aspectos jurídicos, políticos e de sustentabilidade. Palmas, em razão desse processo de ocupação desordenado, expansão sem adensamento, possui o maior custo per capita de urbanização do País, estimado em R\$ 216,79, apontado pela Figura 2 abaixo. Este custo comparado com Belém/PA cai para R\$ 84,27, e com Goiânia/GO para R\$ 65,72. (BAZOLLI, 2015, p. 56). Essa condição mostra claramente a consequência da ocupação da cidade com baixa densidade e com a retenção de terras, além de se 
constatarem grandes espaços urbanizados vazios na região central; em contraposição, espaços adensados precários, sem urbanização, na periferia.

Figura 2. Relação entre densidade demográfica e custo de urbanismo per capita em capitais selecionadas - em reais ( $R \$$ ) 2005.

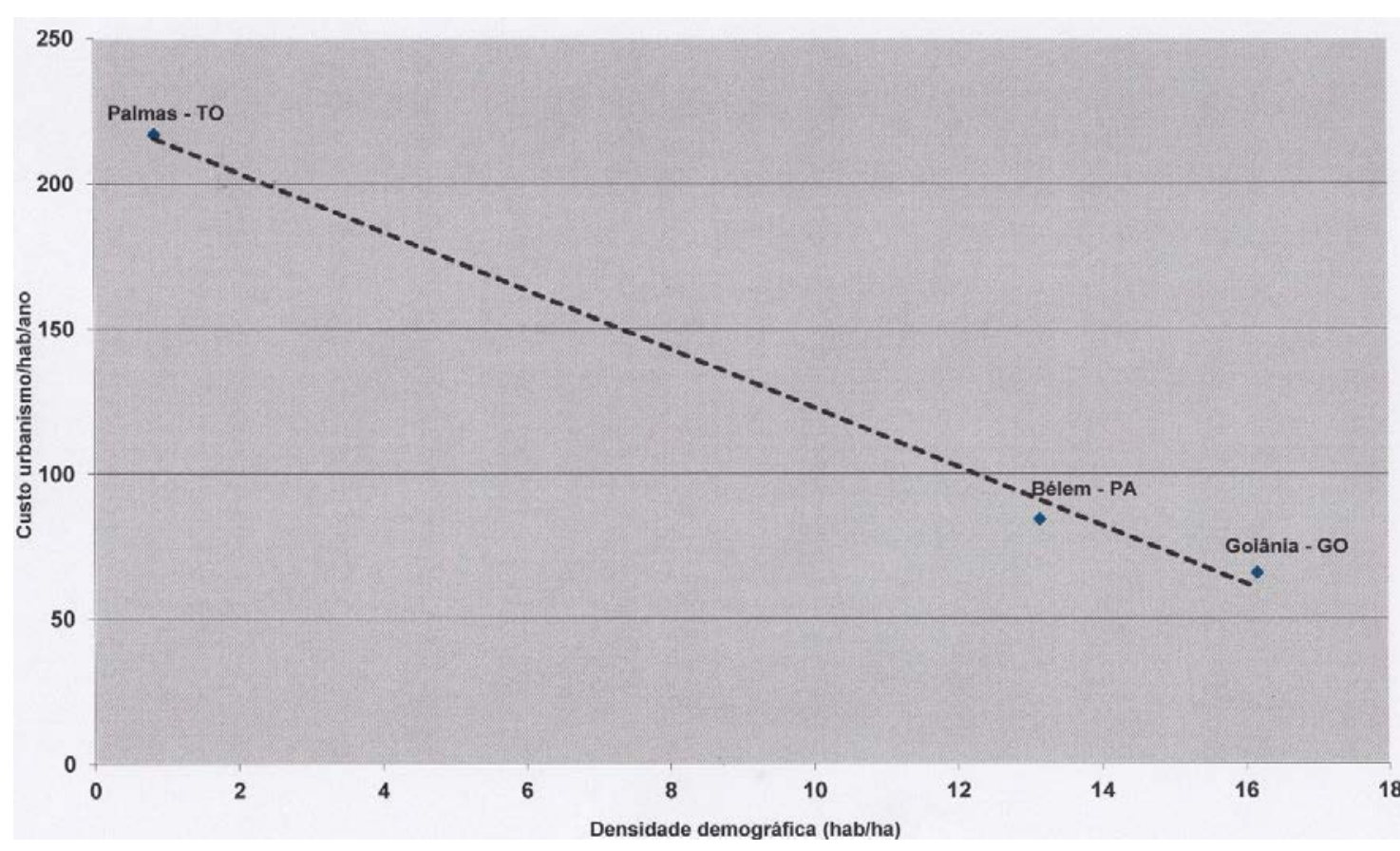

Fonte: (BAZOLLI, 2015, p. 57)

Porém, e mesmo diante de um quadro desfavorável, o ímpeto econômico pela expansão urbana não foi contido na cidade. Em 2011, houve uma grande movimentação nesse sentido, pretendia-se expandir a cidade para as regiões norte e leste. E recentemente, no final de 2015, foise retomado o processo de interesse pela expansão urbana. O Executivo municipal pretende na revisão decenal do Plano-Diretor criar novas áreas urbanas, denominadas "áreas ou zonas de contenção". Pontuamos que, embora o Poder Público municipal pretenda criar uma regulamentação de uso diferente para essas áreas, não haverá como conter a especulação imobiliária, pela expectativa de implantação de loteamentos nessa região. Pode-se então concluir que o resultado desse processo expansivo será o da reprodução do atual problema das grandes cidades brasileiras, ou seja, o da "criação da periferia, da periferia". Essa nova configuração expulsará os pobres para além da periferia, àquela inexistente ao olhar dos gestores locais.

Dessa maneira, seria necessário convergir o discurso ao menos para pôr em crise falácias dominantes, como a de que a expansão urbana produz ofertas e equilibra os preços da terra. Para mitigar a questão de moradia na cidade, seria necessário promover o acesso à terra urbanizada. 
Portanto, a questão não é quantidade de oferta de solo urbanizável, medida que torna as cidades insustentáveis, mas a de ofertar e dar acesso ao solo urbanizado, centralizado e provido. O preço do solo não é mensurado em razão da quantidade, e sim da qualidade. Assim, medidas desse tipo são benéficas somente ao mercado especulativo, com efeitos desastrosos pela insustentabilidade ambiental e pelo custeio público de urbanização, demonstrado na Figura 2, anterior.

Portanto, esse quadro apresentado em Palmas contextualiza a necessidade da aplicação de instrumentos urbanísticos de contenção da expansão urbana, de promoção do acesso aos vazios urbanos na região central, e da obtenção do equilíbrio nos valores praticados pelo setor imobiliário. Nesse viés, o Plano-Diretor Municipal de Palmas - Lei Complementar de no 155 (PALMAS, 2007) -, previu no art. 5o, inciso I, atendendo aos preceitos constitucionais regulamentados pelo Estatuto da Cidade, "o princípio da função social" e estabeleceu no art. 70 que "a propriedade urbana cumpre sua função social quando atende prioritariamente ao interesse coletivo da sociedade. " E, para a promoção, planejamento, controle e gestão de desenvolvimento municipal este diploma legal criou nos termos do art. 74, inciso II, os "instrumentos jurídicos, econômicos e urbanísticos", entre eles o que está previsto na alínea "a" do PEUC, tema deste estudo.

Para a instrumentalização e a aplicação do PEUC, estabeleceram-se as regras previstas a partir do art. 75 desta Legislação Urbanística municipal (PALMAS, 2007), determinando que "são passíveis de parcelamento, edificação ou utilização compulsórios o solo urbano não-edificado, subutilizado ou não-utilizado, localizado nas áreas de ocupação prioritária e de ocupação preferencial, da área urbana da sede do município, desde que possuam infraestrutura básica. " Entretanto, observa-se no texto legal "uma confusão entre os conceitos de imóvel não utilizado e imóvel subutilizado, de forma que ambos são tratados como se fossem um só fenômeno." Constata-se que incorretamente "os conceitos utilizados para delimitar os casos de subutilização são os mesmos adotados para os imóveis não edificados e não utilizados, respectivamente. " (IPEA, 2015, p. 57).

Denota-se, porém, que, em razão da extensão de vazios urbanos em Palmas, este instrumento tenha a finalidade precípua de atingir os lotes vazios; nota-se essa intenção no texto deste mesmo artigo, no inciso IV, ao prever "uma caracterização que muito mais se aproxima daquilo que é compreendido como imóvel não edificado. " (Ibid., p. 57).

A Lei municipal regulamentadora deste instrumento - Lei Complementar no 195 (PALMAS, 2009) - especificou que o imóvel subutilizado e/ou não utilizado é "aquele cuja área construída 
seja inferior a $10 \%$ da área permitida para edificação no lote; aquele cujo investimento na edificação for incompatível com o valor do lote; edificações que tenham permanecido sem uso por período igual ou superior a cinco anos; lotes ou glebas vazias em áreas dotadas de infraestrutura básica. Salienta-se que a Legislação em pauta no art. 4ํ possibilita aos proprietários dos imóveis passíveis da aplicação do PEUC propor ao Executivo municipal o estabelecimento do Consórcio Imobiliário, na forma do Estatuto da Cidade.

Nesse sentido, para a aplicação do PEUC, necessitar-se-ia que os possuidores de imóveis, nas condições acima especificadas, fossem identificados e notificados para que protocolassem no prazo máximo de um ano a aprovação do projeto de parcelamento ou de edificação, para serem iniciados no prazo máximo de dois anos a contar da aprovação do parcelamento ou da emissão do Alvará de Construção, ficando o adquirente com os encargos, caso houvesse a transmissão do imóvel posterior à data da notificação. (PALMAS, 2007, art. 76.).

Importante salientar que em Palmas o fato de a Lei Complementar no 195 (PALMAS, 2009) estabelecer no art. $3 \circ$, $\S \S 1$ e 2 , o prazo para conclusão da obra, "merece destaque" por extrapolar "aquilo que foi originalmente concebido no Estatuto da Cidade. Esses dispositivos conferem mais concretude à legislação municipal, o que possibilita mais segurança na aplicação do PEUC." (IPEA, 2015, p. 62).

Portanto, o descumprimento das etapas previstas pelo instrumento resultaria na aplicação de alíquotas progressivas do Imposto sobre a Propriedade Predial e Territorial Urbano (IPTU), mediante a majoração da alíquota e respeitado o prazo instituído na Legislação vigente. Decorridos os cinco anos de cobrança sem que o proprietário tenha cumprido a obrigação de parcelamento, edificação ou utilização, o município poderia proceder à desapropriação do imóvel com pagamento em títulos da dívida pública. (PALMAS, 2007, arts. 77 e 78).

Como já mencionado anteriormente, para a implantação do PEUC em Palmas, foi necessário aprovar legislação específica, regulamentando o Plano-Diretor (PALMAS, 2007). A Lei especifica foi encaminhada pelo Executivo municipal à Câmara de Vereadores no mês de julho de 2009, para exame, discussão e aprovação. Descrevemos na sequência o trâmite legislativo exaustivo e a árdua e legítima disputa dos agentes interessados pelo espaço urbano.

\section{O PROCESSO LEGISLATIVO DO PEUC, EM PALMAS}

Em breve resgate ao trâmite legislativo, destaca-se que a matéria foi discutida por aproximadamente cinco meses, e mesmo assim gerou polêmica no dia da sua votação final. $\mathrm{O}$ 
Executivo municipal encaminhou o Projeto de Lei Complementar (PLC) no dia 7 de julho de 2009, que recebeu o número 17, e esteve na pauta do dia 29 de julho. Porém a sua votação foi adiada pela arguição de necessidade de novos estudos e pelo entendimento, por alguns parlamentares, de haver necessidade de uma possível reformulação na proposta do PLC. Dessa maneira, o PLC foi encaminhado à Comissão de Administração Pública, Urbanismo e Infraestrutura Municipal, presidida na ocasião pelo vereador Fernando Rezende (DEM). Este fato gerou insatisfação da população em razão de o presidente dessa comissão ser o fundador do Sindicato das Empresas Imobiliárias (SECOVI-TO), licenciado para o exercício parlamentar, alinhando a questão ao visível interesse do setor imobiliário, por esta matéria.

Dessa maneira, o debate na Câmara de Vereadores perpassou pela disputa do setor imobiliário e o seu interesse de protelação da aplicação do PEUC, pelo motivo da prática corriqueira na cidade de retenção especulativa, especialmente na sua região central. Segundo a Secretaria das Finanças da Prefeitura de Palmas (SEFIN), existem mais de 40 mil lotes vazios particulares na cidade, além de 8 mil lotes em quadras que foram parceladas e estão em locais valorizados pelo mercado imobiliário, de propriedade do Governo do Estado do Tocantins, e uma grande quantidade de glebas que ainda não foram micro parceladas.

Nesse contexto, o presidente da Comissão de Administração Pública, Urbanismo e Infraestrutura Municipal da Casa Legislativa, citado anteriormente, acatou duas emendas ao PLC, de interesse do mercado imobiliário. A primeira buscava retirar a aplicabilidade do PEUC sobre os lotes multifamiliares, em razão de esses imóveis fazerem parte de um nicho importante para esse setor no processo de verticalização da cidade, dentro de uma lógica de maximização da lucratividade. A segunda tentava prorrogar o prazo para a aplicação da lei que instituía o PEUC por dois anos. Entretanto, as emendas foram vencidas na sessão parlamentar de dezembro de 2009, que, em bloco, foram retiradas por maioria de votos.

Os parlamentares defensores da proposta de modificação que objetivava estender a vigência da lei para o prazo de dois anos sustentavam que o prazo de um ano para a adequação aos proprietários à nova legislação seria exíguo, considerando fosse imediata a sua vigência. Nesse sentido, não foi levado em conta por estes parlamentares de que o Plano-Diretor de Palmas previa esse instrumento urbanístico o PEUC desde 2007, razão de não haver motivos dessa pretensão prorrogativa de vigência. Esse argumento, o da anterioridade, sustentou a tese dos vereadores que refutavam o pedido de prorrogação da vigência. Assim, sob esse crivo, a lei regulamentadora desse instrumento primordial para a gestão do território foi aprovada, e com vigência imediata. 
O PLC, no que se refere ao território de abrangência do PEUC seguiu a orientação do PlanoDiretor municipal, conforme mostra a Figura 3, que previa sua aplicação sobre os lotes comerciais em áreas centrais, ao longo da Avenida Teotônio Segurado e Avenida JK; nos lotes compreendidos entre o Córrego Brejo Comprido e o Ribeirão Suçuapara; propriedades de até dez lotes unifamiliares ou lotes multifamiliares superiores a $2.000 \mathrm{~m}^{2}$, compreendidos entre a Área Residencial Sudoeste 151 e Área Residencial Noroeste 71, e Área Residencial Sudeste 151 e Área Residencial Nordeste 71.

Figura 3. Áreas definidas para aplicação do PEUC

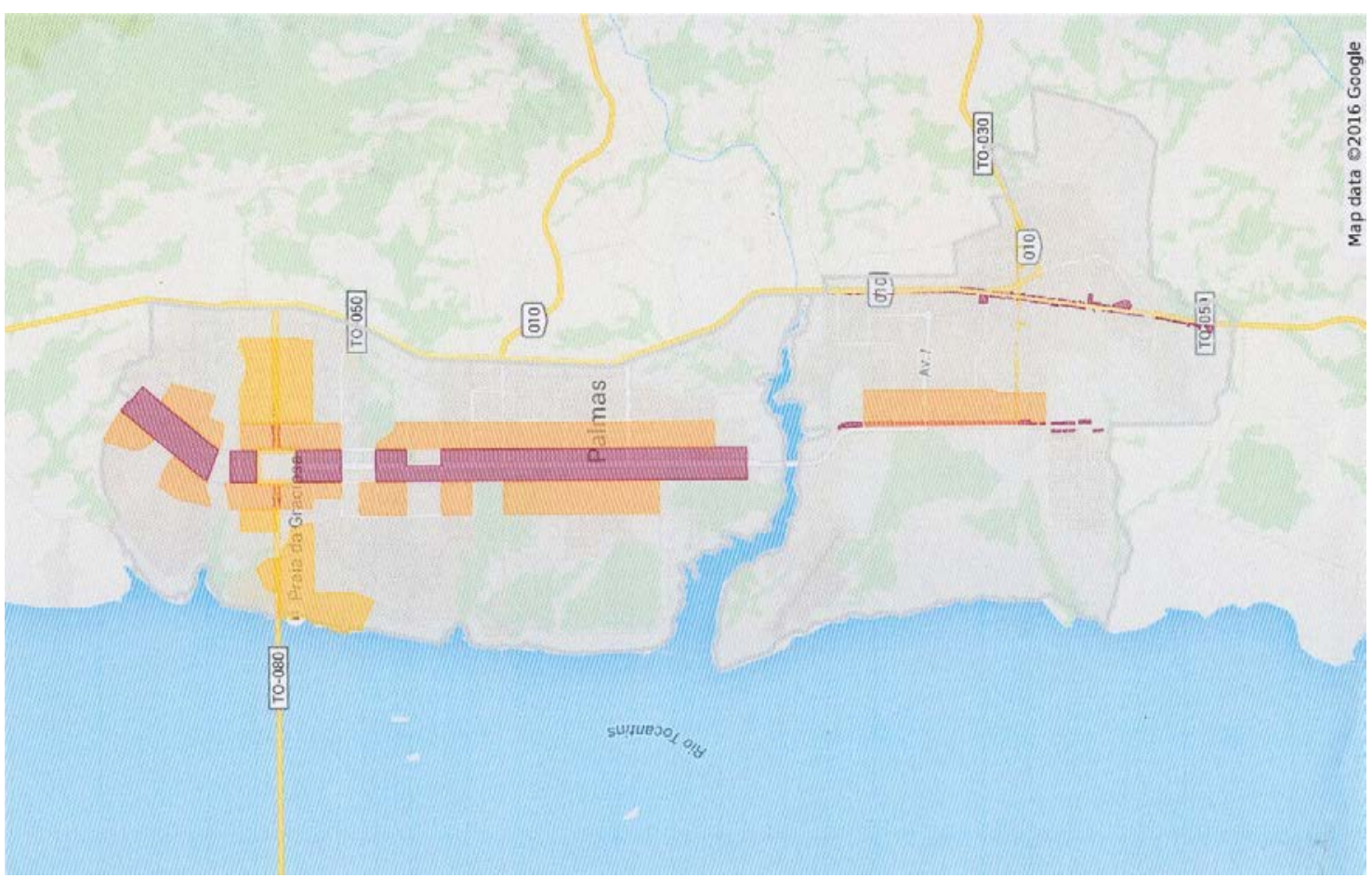

Fonte: (PREFEITURA, 2009)

Nesse contexto de lamentações, disputa do espaço urbano e de um longo, acirrado e exaustivo debate na Câmara Municipal, em dezembro de 2009, a Lei Complementar de no 195 (PALMAS, 2009), que instituiu o PEUC, foi aprovada.

\section{A APLICAÇÃO DO PEUC, EM PALMAS}

Após a aprovação do instrumento de regulamentação (PALMAS, 2009) do PEUC, seria importante salientar algumas contradições entre a redação da Lei e a aplicação do instrumento. Verifica-se no art. 2 q que o PEUC seria aplicado nas áreas previstas pelo Plano-Diretor municipal 
em etapas sucessivas de notificações, e numa primeira etapa nas áreas de ocupação prioritária e preferencial. O referido artigo define que as edificações compulsórias seriam passíveis de notificações aos imóveis inseridos na área de Urbanização Prioritária, e o parcelamento compulsório, às glebas urbanas pertencentes às áreas de Ocupação Prioritária e de Ocupação Preferencial. Entretanto, sem motivo justificável, a sequência preconizada pela Lei é interrompida pela interpretação dada ao $\S 3$ o deste mesmo artigo, ao especificar "As etapas posteriores serão definidas em leis específicas". Isso significa que as etapas seguintes dependeriam da aprovação das referidas leis específicas, deduzindo-se, então, que a cada grupo de notificações poderia haver a possibilidade de interrupções sine die.

Importante salientar que o legislador demonstrou a pretensão de incentivar a edificação compulsória às regiões no entorno das avenidas comerciais equipadas com infraestrutura urbana Theotônio Segurado e Juscelino Kubistchek -, com a finalidade de provocar o adensamento desses eixos. Observa-se que esta estratégia segue ao previsto no Plano-Diretor municipal, qual seja, a de compelir os possuidores de imóveis vazios em áreas dotadas de infraestrutura urbana a cumprir a função social da propriedade, com o objetivo de adensar os eixos viários e de transporte coletivo urbano. Pontuando que no eixo da Theotônio Segurado se concentra a maior extensão de vazios urbanos da região central da cidade. Porém, nota-se que se as ações definidas pela Lei (PALMAS, 2009), que regulamenta o PEUC, não forem combinadas aos outros instrumentos do Estatuto da Cidade (BRASIL, 2001), não surtirá o efeito de atender à demanda pelo adensamento necessário à cidade, como será demonstrado neste estudo.

Há de se ressaltar que a regulamentação do PEUC, em Palmas, data de 2009 (PALMAS, 2009), mas o instrumento somente foi utilizado pela municipalidade a partir de 2011, quando aconteceram as primeiras notificações restritas à primeira etapa prevista pela citada Legislação. Importante destacar a dificuldade dos municípios para a execução das notificações, especialmente no caso de Palmas onde pessoas adquiriram lotes para especular e "grande parcela dos proprietários reside fora do município. " (IPEA, 2015, p. 88), razão para a Prefeitura ampliar "o aporte de recursos materiais e financeiros para a execução das notificações". (Idem). Luiz Masaru Hayakawa (2014), presidente do Instituto Municipal de Planejamento Urbano de Palmas (IMPUP), afirmou que em "estudos realizados recentemente, constatou-se que sessenta e cinco por cento dos vazios urbanos, seus proprietários nem sequer residem em Palmas. " (PALMAS, 2014, p. 17).

Mesmo diante dos desafios apresentados para a aplicabilidade do PEUC, em 2010, o Conselho de Desenvolvimento Urbano e Habitação de Palmas recomendou (PALMAS, 2010, pp. 12- 
13) à Prefeitura fossem emitidas as notificações aos proprietários enquadrados na Legislação pertinente aprovada desde 2009, porém a recomendação foi ignorada.

Portanto, como referido anteriormente, somente em 2011 a Prefeitura de Palmas passou a aplicar O PEUC; emitiu 254 notificações, para edificação, e 8 notificações para parcelamento compulsório (PALMAS, 2011, pp. 3-4), dirigidas aos proprietários enquadrados na Legislação (PALMAS, 2009), porém cancelou-as em razão da identificação de "[...] vícios de validade nos atos praticados." (IPEA, 2015, p. 34), que foram motivados por "[...] falhas, irregularidades e incorreções procedimentais. " Este cancelamento objetivou "[...] promover correções necessárias e recomeçar o processo." (Ibid., p. 104)

Percebeu-se, então, que o ato de notificação ao proprietário seria um dos principais fatores de insegurança para os municípios na aplicação do PEUC, em razão de questões ainda pendentes de debates, como a validade postal (ao residente e ao não residente) e a garantia do recebimento (remessa pelo correio). (IPEA, 2015, p. 105). Também pendem ao PEUC questões jurídicas, como a instância apropriada para a notificação: a do Cartório de Registros de Títulos e Documentos ou a do Poder Público Municipal. (Idem)

Contudo, constata-se que "[...] municípios iniciam as notificações" sem "[...] o delineamento de estratégias espaço-temporais relacionadas às diretrizes da política urbana", e sem "estabelecer mecanismos de acompanhamento e controle." (IPEA, 2015, p.105). Evidente que o cancelamento, pela Prefeitura de Palmas, das notificações realizadas em 2011 causou atraso nas medidas de planejamento urbano (essencialmente relacionado ao da ocupação dos vazios urbanos) e considerável prejuízo financeiro ao erário (em números não revelados).

Finalmente, quase quatro anos após a aprovação da lei regulamentadora (PALMAS, 2009) do PEUC, no final de 2013, notificaram-se, na chamada primeira fase, 159 proprietários de terrenos (lotes) para edificação compulsória (PALMAS, 2013, pp. 18-19). Desta feita, a Prefeitura tentou aprimorar o procedimento administrativo e, no sentido de assegurar os efeitos legais do resultado das notificações, expediu o Decreto no 699 (PALMAS, 2014, p. 4), regulamentando as condições e os prazos de trâmite desses documentos (notificações).

A população de Palmas demonstrou grande interesse pela medida tomada, razão pela qual foi destaque na imprensa e objeto de vários depoimentos dados pela Prefeitura, entre eles destacou-se o do prefeito Carlos Amastha que se pronunciou em relação à medida (aplicação do 
PEUC): "Isso significa a arrecadação de mais de $\mathrm{R} \$ 40$ milhões"; ${ }^{2}$ na nossa análise, contradizendo integralmente a proposta originária do instrumento, não poderia estar atrelado somente ao aumento de arrecadação, mas especialmente ao resultado de Planejamento relacionado à ocupação dos vazios urbanos centrais.

Em Palmas, embora a Secretaria Municipal de Meio Ambiente e Desenvolvimento Urbano indicou a região a ser notificada para a aplicação do PEUC, "o que é mais adequado, tendo em vista que o objetivo maior do instrumento é a indução ao cumprimento da função social da propriedade articulada a uma lógica territorial de planejamento e gestão" (IPEA, 2015, p. 81), o processo segue para o controle da Secretaria de Finanças (SEFIN), conforme especifica o art. 8o, inciso III, da Lei Complementar no 195 (PALMAS, 2009), demonstrando, assim, que o instrumento está sendo confundido pelos gestores locais, que o priorizam como um recurso para arrecadação de impostos. Os vários depoimentos na imprensa da Prefeitura sobre o PEUC constatam essa pretensão. Citamos o salto da arrecadação, em Palmas, do IPTU, entre 2008 e 2014, "de 1.115\%", 3justificado pela Secretaria das Finanças; entre os vários fatores, o da aplicação do IPTU progressivo. Evidente que, em análise aprofundada, constata-se que a adição de recursos resultante da aplicação do PEUC não seja tão significativa. Porém, pode-se constatar o reforço nesse discurso de vinculação do aumento da arrecadação municipal ao PEUC, isto com a finalidade de destacar a sua aplicação ao resultado econômico e não ao de planejamento urbano, esse último ainda sem efetividade. Nessa mesma linha de debate, em abril de 2016, a mesma Secretaria (SEFIN) declarou que "algo em torno de R\$ 10 milhões deixa de ser arrecadado pelos cofres da Prefeitura de Palmas, referente a imóveis não edificados e que se enquadram no IPTU progressivo. " [...] "são terrenos que ocupam grandes áreas.". ${ }^{4}$ Nota-se então que, se por um lado há o tratamento da questão atrelada à arrecadação, um fator econômico, por outro se constata e evidencia a falta de organização na condução da aplicação desse instrumento. Para além disso, retornaremos a esse debate em razão de este estudo constatar que a aplicação do instrumento tem se concentrado sobre pequenas

\footnotetext{
${ }^{2}$ HENRIQUE, Luiz. IPTU Progressivo é arma contra especulação imobiliária em Palmas. Revista Mãos à obra. 11 jul. 2013. Caderno Legislação. Disponível em: https://maosaobratocantins.wordpress.com/2013/07/11/iptu-progressivo-e-arma-contra-especulacaoimobiliaria-em-palmas/. Acesso em 11 set. 2015.

3 Jornal do Tocantins. dez 2015. Camylla Costa. Caderno Economia. Arrecadação de Palmas salta 1.115\% em seis anos. Acesso em abril $2016 . \quad$ Disponível <http://www.jornaldotocantins.com.br/editorias/economia/arrecada\%C3\%A7\%C3\%A3o-de-palmas-salta-1115-em-seis-anos-1.1008225>

4 Jornal do Tocantins. abril 2016. Fábio Coêlho, Caderno Economia. Imposto progressivo gera resultados. Acesso em abril 2016. Disponível em: <http://www.jornaldotocantins.com.br/editorias/economia/impostoprogressivo-gera-resultados-1.1063149>
} 
áreas, fato confirmado por esta declaração da Prefeitura, de não haver aplicação do PEUC sobre grandes áreas.

Entre os vários agentes impactados pela implantação do PEUC, destacamos a reação do Conselho Regional de Corretores de Imóveis (CRECI-TO), que se manifestou contrário à medida. Segundo o diretor João Batista Ferreira Alves, "O IPTU progressivo prejudicou os negócios para muitos corretores de Palmas", ${ }^{5}$ em razão da redução de negócios imobiliários que seriam coibidos pela força vinculante ao adquirente, pela aplicação do instrumento. A posição se justifica em razão de esses profissionais estarem acostumados a oferecer lotes aos "investidores" imobiliários que o usam para retenção, esperando uma boa margem de "lucro" na revenda, dentro da lógica ao fomento da especulação imobiliária.

No conjunto de medidas tomadas para a aplicação do PEUC foi aprovada a Lei Complementar de no 280 (PALMAS, 2013), que alterou o Plano-Diretor municipal, ampliando a área de ocupação preferencial da Avenida Juscelino Kubistchek com mais duas quadras. Objetivou-se incluir estas áreas que, por similitude às sujeitas ao PEUC, estavam passando por um processo de valorização imobiliária em razão da ausência da aplicação do instrumento.

Segundo a Secretaria das Finanças Municipal (SEFIN), as informações necessárias para a elaboração de uma listagem de cerca de mil propriedades foram extraídas do banco de dados do município pela Secretaria de Desenvolvimento Urbano (SEDU), no qual constam as áreas construídas dos imóveis, o que possibilitou o cálculo do coeficiente de aproveitamento efetivamente implantado em cada um e, consequentemente, o enquadramento na condição de passíveis de exigibilidade quanto ao parcelamento ou edificação, compulsórios.

Segundo o prefeito Carlos Amastha, existem "sete milhões de metros quadrados de vazios urbanos da Capital” ${ }^{6}$ passíveis de se enquadrarem como áreas notificáveis na forma especificada pelo Plano-Diretor municipal e pelo Decreto expedido para a notificação aos proprietários (PALMAS, 2015). Portanto, tem-se um longo caminho a ser percorrido para instrumentalizar ações de adensamento na região central da cidade.

\footnotetext{
5 Jornal do CRECI. Para o CRECI-TO o IPTU progressivo prejudicou alguns negócios. Acesso em: dez 2015. Disponível em: <http://www.crecito.org.br/index.php/noticias/156-para-o-creci-to-o-iptu-progressivoprejudicou-alguns-negocios. Acesso em 13 jul. 2015>

${ }^{6}$ HENRIQUE, Luiz. IPTU Progressivo é arma contra especulação imobiliária em Palmas. Revista Mãos à obra. 11 jul. 2013. Caderno Legislação. Disponível em: https://maosaobratocantins.wordpress.com/2013/07/11/iptu-progressivo-e-arma-contra-especulacaoimobiliaria-em-palmas/. Acesso em 11 set. 2015.
} 
Entretanto, o escalonamento das notificações deverá estar relacionado à demanda do mercado imobiliário, pois se houvesse notificação de toda área prevista pela Legislação (PALMAS, 2009), não se conseguiria absorver a entrada "de 20 a 30 mil lotes" $^{7}$ neste mercado, em um mesmo momento.

Portanto, será necessário mensurar e não disponibilizar "um percentual do estoque de terras maior do que a capacidade de absorção do mercado e do setor público, porque isso poderia comprometer a própria consolidação do instrumento. " (IPEA, 2015, p. 74).

Nesse contexto, Palmas deu continuidade aos procedimentos para a aplicação do PEUC, em dezembro de 2014, emitiu 241 notificações para edificação e 3 notificações para parcelamento, compulsórios (PALMAS, 2014, pp. 19-21), dirigidas aos proprietários enquadrados pela Legislação (PALMAS, 2009). Os resultados das notificações encaminhadas foram: apresentação de 8 pedidos de Alvarás de Construção; expedição de 85 "Habite-se" e 205 lançamentos de Imposto Predial Territorial Urbano progressivo no tempo aos inadimplentes (PALMAS, 2015, pp. 9-11), incluindo-se as notificações anteriores. Dos notificados, $45 \%$ não residem na cidade, já havíamos alertado anteriormente para a dimensão dessa situação peculiar a Palmas.

Importante salientar a dedução acerca da aplicação do PEUC em Palmas, em relação aos vazios urbanos na cidade. Verifica-se que dos sete milhões de metros quadrados vazios existentes em 2015, concretizaram-se com 205 lançamentos no PEUC, o correspondente a apenas 276,2 mil metros quadrados, que estão distribuídos pelas regiões mostradas na Tabela 1. Portanto, é possível afirmar que esses números ratificam a distância entre o montante de espaços vazios e a eficácia da aplicação desse instrumento na cidade. Nessa proporção de lançamentos, o Poder Público não conseguiria atingir as propriedades vazias antes de um prazo estimado em trinta anos.

\footnotetext{
${ }^{7}$ Estudo realizado pelo Instituto de Planejamento Urbano de Palmas. Conselho de Desenvolvimento e Habitação de Palmas. Diário Oficial do Município de Palmas. Palmas, TO, v.1. № 869, 18 out. 2013, p. 14.
} 
Tabela 1. Lançamentos IPTU progressivo 2015

\begin{tabular}{|c|c|c|c|}
\hline Região & Lançamentos & Região & Lançamentos \\
\hline ACNE I & 5 & ARSE 14 & 4 \\
\hline ACSE I & 6 & ARSE 21 & 14 \\
\hline ACNE II & 5 & ARSE 41 & 40 \\
\hline ACSE II & 6 & ARSE 51 & 1 \\
\hline ACSU SE 60 & 2 & ARSE 61 & 12 \\
\hline ARNE 12 & 13 & ARSE 71 & 8 \\
\hline ARSE 12 & 25 & ARSE 81 & 9 \\
\hline ARNE 13 & 15 & ACSV SE 41 & 1 \\
\hline ARSE 13 & 21 & ACSV SE 71 & 1 \\
\hline ARNE 14 & 17 & TOTAL & 205 \\
\hline
\end{tabular}

Fonte: Diário Oficial do Município de Palmas (PALMAS, 2015, pp. 9-11)

Entretanto, a Prefeitura de Palmas, ao dar continuidade aos procedimentos para a aplicação do PEUC, reduziu, em dezembro de 2015, para apenas 91 notificações, todas para edificação compulsória (PALMAS, 2015, p. 7), dirigidas aos proprietários enquadrados pela Legislação (PALMAS, 2009). Observa-se, então, significativa redução no número de notificações, e novamente as áreas maiores carentes de parcelamento são poupadas deixando de ter a merecida atenção.

Em análise às áreas de incidência de lançamento do IPTU progressivo, verifica-se que, entre as glebas incluídas nas notificações do PEUC, duas de propriedade da Empresa Sul Americana de Montagens S.A. (EMSA) recebidas em dação em pagamento pelo Governo do Estado pelo serviço de infraestrutura urbana, prestado na ocasião da formação da cidade, foram parceladas. A Quadra 505 Sul está sendo comercializada pela empresa ao preço do lote, em média de $R \$ 417,00$ o metro quadrado; e a Quadra 109 Sul foi vendida com a grife da Alphaville, pelo valor médio de R\$ 600,00 o metro quadrado. Portanto, é possível deduzir que o PEUC em Palmas não conseguiu cumprir o seu papel de promover o acesso igualitário à terra urbanizada, essa fatia de mercado está sendo reservada para a classe alta.

Há de se considerar também a ausência completa da recuperação da mais-valia pelo Poder Público local. Em análise ao mercado imobiliário, pôde-se constatar que a Quadra 505 Sul, ainda sem infraestrutura, tinha o valor venal expresso na Planta Genérica de Valores do município, de R\$ 43,20 o metro quadrado (2012); ao receber a infraestrutura passou para $\mathrm{R} \$ 138,00$ o metro quadrado (2013), e está sendo vendida pelo mercado imobiliário a $\mathrm{R} \$ 417,00$ o metro quadrado (2014). Nesse contexto, fica evidente o crescimento exponencial do lucro imobiliário sobre a terra. 
Portanto, nota-se que os especuladores socializam o custo da cidade ao receber a urbanização do setor público e individualizam os lucros na venda do imóvel.

\section{CONSIDERAÇÕES FINAIS}

Entende-se que o PEUC é um instituto ainda em construção; por esse motivo, requer a reflexão sobre dois pontos fundamentais, geralmente ignorados: i) vê-lo como instrumento de planejamento, e não com finalidade de aumento de arrecadação; ii) entendê-lo como um mecanismo para possibilitar o acesso à terra urbanizada ao ser conjugado com outros instrumentos do Estatuto da Cidade.

No caso específico de Palmas, havia uma estimativa de 300 notificações anuais anunciada pela Prefeitura, na área estabelecida pela Lei regulamentadora (PALMAS, 2009). Porém, em 2015, conforme mostrado acima, ocorreram apenas 91 notificações (PALMAS, 2015, p.7). Discute-se, também, se a aplicação dessa estratégia conseguiria ter a efetividade de reduzir os vazios urbanos na cidade, conter a especulação imobiliária e dar acesso à terra urbanizada.

Em análise ao contexto local, deduz-se que a dinâmica empreendida na aplicação do PEUC não leva em conta a dimensão do problema fundiário da cidade, em razão da premência no aprofundamento do debate acerca da organização dos espaços urbanos em Palmas.

Nota-se que se num universo de sete milhões de metros quadrados vazios na cidade, passados nove anos da aprovação do Plano-Diretor municipal (PALMAS, 2007) e sete anos da aprovação da Legislação que regulamenta o PEUC, conseguiu-se ínfimo resultado de apenas 276,2 mil metros quadrados, lançados no IPTU progressivo, há de se preocupar, repensar e promover amplo debate acerca da efetividade desse instrumento.

Entre os fatores positivos e negativos, constatamos como positivo neste estudo terem sido notificados 40 proprietários de uma das quadras mais valorizadas da cidade (504 Sul), conforme mostra a Tabela 1. Há de se convir que, embora esses lotes tenham em torno de 450 metros quadrados, seus valores de mercado são elevados, e a aplicação do instrumento força o resgate do equilíbrio mercadológico. De outro modo, destacamos como negativos e críveis de crítica as notificações e os lançamentos em lotes de apenas 121 metros quadrados em detrimento às grandes áreas - glebas inteiras -, porquanto não se têm claros o motivo e a justificativa dessa inversão na escolha. 
Como já afirmado anteriormente, não faz sentido aplicar o PEUC isoladamente. O Poder Público deveria agregar o instrumento a um conjunto de medidas, que garantissem o direito à cidade.

Diante do quadro apresentado pelo estudo, é possível concluir que não há efetividade do PEUC da forma como a Prefeitura de Palmas vem aplicando o instrumento, em razão de a medida não impactar significativamente nos valores praticados pelo mercado imobiliário; de não dinamizar os consórcios imobiliários permitidos pela Legislação, pois os que tivemos foram realizados em regiões distantes da cidade e sem planejamento financeiro; de não incluir de imediato as glebas (áreas de grandes dimensões) que estão previstas pela Legislação e sendo poupadas; de ser tratado com fins arrecadatórios e estar vinculado às finanças do município; de não estar associado a outros instrumentos do Estatuto da Cidade (BRASIL, 2001); e, finalmente, ao invés de contribuir para a função social e acesso à terra urbanizada, estar fomentando a proliferação da oferta de condomínios horizontais, destinados à classe alta.

Questiona-se, ao analisar a aplicação do PEUC no seu papel precípuo de indutor à mudança de comportamento dos agentes econômicos em Palmas, uma maior transparência no andamento dos processos a partir das escolhas das áreas que serão notificadas; a falta do planejamento para o uso dos recursos financeiros e patrimoniais resultantes dos recursos arrecadados e da desapropriação-sanção; a falta de definição clara da estratégia no escalonamento das notificações; e o caráter informativo de outras ações relacionadas ao instrumento.

Esperava-se que, uma legislação inovadora, contextos políticos e ideológicos favoráveis contribuíssem para a efetividade na aplicação do instrumento urbanístico PEUC. Porém, a análise da aplicação e dos resultados, discutidas por esse estudo, leva-nos a concluir que o PEUC em Palmas não vem conseguindo cumprir o seu papel precípuo de indutor à mudança de comportamento dos agentes econômicos, isto pelas razões já expostas. Para haver avanço nesse debate depende da mudança no olhar e do tratamento do instituto pela Prefeitura; da vontade política, da quebra da forte resistência pelo setor imobiliário e, também, do aumento da sua escala local de aplicação, pois, verifica-se que no âmbito territorial estão sendo poupadas as grandes áreas. Esses motivos reforçam a assertiva de que nos resultados da aplicação incipiente do PEUC em Palmas não são perceptíveis, tratando-se da efetividade em relação ao objetivo precípuo, o seu papel coercitivo de fazer cumprir a função social da propriedade. Essa análise inicial possibilita subsidiar novos estudos para avaliar o efeito da aplicação deste instrumento no valor de mercado dos imóveis e no adensamento da cidade nas regiões onde está sendo aplicado. 


\section{REFERÊNCIAS BIBLIOGRÁFICAS}

BAZOLLI, J.A. A geopolítica da expansão urbana de Palmas. In: BARROS, Patrícia Orfila (Org.). Palmas um projeto e múltiplos olhares. Palmas-TO: Eduft, 2015, pp. 49-62.

BRASIL. Constituição. Constituição da República Federativa do Brasil. Brasília, DF: Senado Federal, 1988.

$\begin{aligned} \text { julho } & \text { Constituição. Constituição da República dos Estados Unidos do Brasil. Rio de Janeiro.16 de } \\ \text { de } 1934 . & \text { Disponível }\end{aligned}$ http://www.planalto.gov.br/ccivil_03/Constituicao/Constituicao34.htm. Acesso em: 25 set 2011.

Lei n. 10.257, de 10 de julho de 2001 (Estatuto da Cidade). Regulamenta os artigos de n.182 e n.183 da Constituição Federal e estabelece diretrizes gerais da política urbana e dá outras providências. Diário Oficial da República Federativa do Brasil, Brasília, DF, v.1, n. 133, 11 jul. 2001. Seção 1, pp. 1-5.

CYMBALISTA, R. O uso de instrumentos requer atitude: $O$ estatuto da cidade. Jornal do Tocantins, Palmas, v. 1, n. Caderno Especial Aurenys, p. 6, set, 2010.

DI SARNO, D. C. L. Elementos do direito urbanístico. Barueri: Manole, 2004.

DIAS, M. L. Notas sobre o direito urbanístico: a "cidade sustentável". Jus Navigandi, Teresina. Disponível em:< http://jus.com.br/revista/texto/1692/notas-sobre-o-direito-urbanistico > Acesso em: 25 set 2011.

HARADA, K. Direito urbanístico: Estatuto da Cidade: Plano Diretor Estratégico. São Paulo: Ndj, 2004. IBGE.Instituto Brasileiro de Geografia e Estatística. Diretoria de Pesquisas - DPE - Coordenação de População e Indicadores Sociais - COPIS. Cidades@. Disponível em:<http://www.cidades.ibge.gov.br/xtras/perfil.php?lang=\&codmun=172100\&search=tocantins $\mid$ palmas/>. Acesso em 12 dez. 2015.

Instituto Brasileiro de Geografia e Estatística. Contas Regionais do Brasil 2012. Rio de Janeiro: IBGE, 2013.

IPEA. Parcelamento, edificação ou utilização compulsórios e IPTU progressivo no tempo: Regulamentação e Aplicação. In: Ministério da Justiça (Org.). Série Pensando o Direito. n. 56. Brasília: Imprensa Oficial, 2015.

MORAES, M. L. A segregação planejada: Goiânia, Brasília e Palmas. Goiânia: UCG, 2003.

PALMAS, (Prefeitura municipal). Lei complementar n. 058, de 15 de setembro de 2002. Institui o Macrozoneamento Territorial do Município de Palmas. Palmas,TO, 15 set. 2002. Disponível em: $<$ www.leismunicipais.com.br/a/to/p/palmas/lei-complementar/2002/5/58/lei-complementar-n-582002-institui-o-macrozoneamento-territorial-do-municipio-de-palmas-e-da-outras--providencias2002-09-16.html>. Acesso em 19 set. 2015.

(Prefeitura municipal). Lei Complementar n. 155, de 28 de dezembro de 2007. Dispõe sobre a política urbana no município de Palmas (Plano Diretor Municipal). Diário Oficial do Estado do Tocantins, Palmas, TO, v. 1, n. 2560, 28 dez. 2007. Seção 1, pp. 182-196

(Prefeitura municipal). Lei complementar n. 195, de 22 de dezembro de 2009. Dispõe sobre a regulamentação e aplicação do Parcelamento, Edificação e Utilização Compulsórios (PEUC) do solo 
urbano não edificado subutilizado ou não-utilizado, da forma que especifica. Diário Oficial do Estado do Tocantins. Palmas, TO, v. 1, n. 3046, 30 dez. 2009. Seção 1, p. 176-177. Republicação: Diário Oficial do Município de Palmas. Palmas, TO, v. 1. N. 10, 6 abr. 2010, Seção 1, pp. 2-3.

(Prefeitura municipal). Conselho de Desenvolvimento Urbano e Habitação de Palmas. Resolução Recomendada n. 5, de 8 de outubro de 2010.Diário Oficial do Município de Palmas. Palmas, TO, v. 1, n. 140, 18 out. 2010, Seção 1, pp. 12-13.

(Prefeitura municipal). Secretaria Municipal das Finanças do Município de Palmas. Edital de Edificação e Parcelamento, compulsórios. Diário Oficial do Município de Palmas. Palmas, TO, v. 1, n. 280, 16 mai. 2011, Seção 1, pp. 3-4.

(Prefeitura municipal). Secretaria Municipal das Finanças do Município de Palmas. Edital de Edificação e Parcelamento, compulsórios. Diário Oficial do Município de Palmas. Palmas, TO, v. 1, n. 918, 31 dez. 2013, Seção 1, p. 18-19.

(Prefeitura municipal). Lei Complementar n. 280, de 18 de julho de 2013. Altera a Lei Complementar 155, de 28 de dezembro de 2007 que dispõe sobre a políticaurbana do município de Palmas, na parte que especifica.Diário Oficial do Município de Palmas, Palmas, TO, v. 1, n. 810, 29 jul. 2013. Seção 1, p. 1.

(Prefeitura municipal). Conselho de Desenvolvimento Urbano e Habitação de Palmas. Ata de Reunião. Diário Oficial do Município de Palmas. Palmas, TO, v. 1, n. 988, 14 abr. 2014, Seção 1, p. 17.

(Prefeitura municipal). Decreto n. 699, de 10 de janeiro de 2014. Regulamenta a notificação para cumprimento de condições e prazos para parcelamento,edificação e utilização compulsória prevista na Lei Complementar 195, de 22 de dezembro de2009.Diário Oficial do Município de Palmas, Palmas, TO, v. 1, n. 925, 10 jan. 2014. Seção 1, p. 4.

(Prefeitura municipal). Secretaria Municipal das Finanças do Município de Palmas. Edital de Edificação e Parcelamento, compulsórios. Diário Oficial do Município de Palmas. Palmas, TO, v. 1, n. 1167, 31 dez. 2014, Seção 1, p. 19-21.

(Prefeitura municipal). Edital de comunicação - IPTU progressivo no tempo. Diário oficial do município de Palmas. Palmas, TO, v. 1. n. 1218, 17 mar. 2015. Seção 1, pp. 9-11.

(Prefeitura municipal). Secretaria Municipal das Finanças do Município de Palmas. Notificação para Edificação Compulsória.Diário Oficial do Município de Palmas. Palmas, TO, v. 1, n. 1412, 31 dez. 2015, Seção 1, pp. 7-8.

SEGAWA, H. Palmas, cidade nova ou apenas uma nova cidade? Revista Projeto, Goiânia, v. 1, no 146, pp. 94-109, out.1991.

TEIXEIRA, L. F. C. A formação de Palmas. Revista UFG, Goiânia, v. 6, no 11, pp. 91-99, jun. 2009.

Trabalho enviado em 21 de junho de 2016.

Aceito em 06 de agosto de 2016. 